\title{
PAIN MINIMIZATION DURING DEHORNING AND DISBUDDING IN GOATS AND GOAT KIDS
}

\author{
Mohan Acharya* \\ Graduate Research Assistant, Department of Animal Science, University of Arkansas, Fayetteville, AR 72701, \\ USA
}

\begin{abstract}
Dehorning and disbudding are the routine management practices in goat farm. Benefit of dehorning and disbudding includes less space required during feeding, easy management, good carcass quality and are required before dairy goats are used as a show animal in the United States. Dehorning is the process of surgically removing horns from adult goats. Dehorning causes severe pain during the surgery and several complications thereafter. Four to six weeks is needed for healing dehorned wound. Dehorning is not generally practiced unless necessary. Disbudding is the process of removing horn buds at an early age. Pain and complications during and after disbudding are less compared with dehorning, nevertheless disbudding causes $100 \%$ increase in blood concentration of stress hormones and kids exhibit stress behaviors. Injection of local anesthetic (lignocaine) alone has no benefit but injection of non-steroidal anti-inflammatory drug (NSAID; meloxicam) before local anesthetic helps to minimize disbudding stress. There are several disbudding techniques. It is necessary to adopt disbudding technique that minimizes stress.
\end{abstract}

Keywords: Anesthesia, dehorning, disbudding, goat, kid, pain

\section{INTRODUCTION}

Dehorning and disbudding is preferred in goats and kids for several reasons such as less fighting with each other, requires less feeding space, easy to handle and easy to market (Alvarez and Gutiérrez, 2010; Alvarez et al., 2015). In the United States, dairy goats are required to dehorn before use as a show animal (Al-Sobayil, 2007). However, dehorning and disbudding involves painful procedure and raises issues of animal welfare (Stafford and Mellor, 2005; Stafford and Mellor, 2011). There are several techniques for dehorning and disbudding (Alvarez and Gutiérrez, 2010; Gascoigne, 2015; Molaei et al., 2015). Very few studies are available that measured stress hormone and stress behaviors during and after dehorning and disbudding. This article summarizes different techniques that minimizes pain during and after these procedures.

\section{Dehorning adult goat}

Dehorning adult goat is a very complicated process therefore generally not preferred. Care should be taken to avoid exposing large sinuses at the base of the horn (Buttle et al., 1986). At first, goat should be sedated with xylazine at the rate of 0.1 to $0.2 \mathrm{mg} / \mathrm{kg}$ intravenously (Hull, 1995). A dose of $10 \mathrm{ml}$ of $2 \%$ lignocaine is sufficient for $45 \mathrm{Kg}$ goat to block lacrimal and infratrochlear nerve. For blocking nerves in each horn $1 \mathrm{ml}$ lignocaine is applied at four different locations (Hull, 1995). Before dehorning, skin around the base of the horn should be incised to prevent regrowth of horn. Horn can be removed using obstetric wire saw or a dehorning saw. Two possible complications are hemorrhage from arteries located at the ventral edge of the horn and opening of large sinuses. Problem of hemorrhage can be resolved by pulling the arteries (Hull, 1995). Prominent hemorrhage can be controlled by thermal cautery (Hull, 1995). Tetanus antitoxin and antibiotics are recommended after horn removal (Buttle et al., 1986). Head bandage for a week is also recommended after surgery (Hull, 1995). A dry scab forms 48 hours after the surgery and for complete healing it will take up to 5 weeks (Hull, 1995). Dehorning during fly season could cause maggot formation (Hull, 1995). Thirty nine percent of producers and $77 \%$ of veterinarians in the United States and Canada use wire saw for dehorning goat (Valdmanis et al., 2007).

*Corresponding e-mail address: macharya@uark.edu 


\section{Mohan Acharya}

\section{Elastrator dehorning}

This method is best to dehorn mature or nearly mature horns. In this method a groove of $1 / 8$ inch deep and $1 / 8$ inch wide is made around the base of the horn (Shelton and Haenlein, 2003). Elastrator is used to stretch a rubber ring and to place it around goat's horn (Marongiu, 2012). Rubber is released over the groove. It usually takes 4 to 8 weeks to slough off horn. It may bleed if horn slough off prematurely, therefore, regular observation is needed. This method doesn't involve injection of anesthesia. In the United States and Canada 36\% of the producers and $3 \%$ of veterinarians prefer elastrator dehorning method for dehorning adult goats (Valdmanis et al., 2007).

\section{Thermal cauterization}

In this method, $1 \mathrm{ml}$ of lignocaine $(20 \mathrm{mg} / \mathrm{ml})$ is administered 15 minutes before disbudding. Two injections are given intramuscularly, first to block corneal branch of lacrimal nerve and second to block cornual branch of the infratrochlear nerve (Alvarez and Gutiérrez, 2010). Electrically heated dehorner is applied for 3 to 4 times ( 3 to 4 seconds each time) in five second interval. In general, heated dehorner is applied until corium of the button is completely cauterized (Alvarez et al., 2015). This is the most common method adopted by veterinarians and producers across the United States and Canada (Valdmanis et al., 2007). An online survey carried out in summer of 2006 reported $97 \%$ of veterinarians and $95 \%$ of producers use thermal cauterization method for disbudding kids (Valdmanis et al., 2007). Plasma cortisol level is generally used as a pain indicator in livestock. A study was done to compare plasma cortisol and pain-related behavior in disbudded kids with or without lignocaine. They concluded that injection of $1 \mathrm{ml}$ of $2 \%$ lignocaine with epinephrine did not prevent acute cortisol secretion and pain-related behaviors in kids (Alvarez, 2015). Cortisol levels in lignocaine administered and cauterized kids were increased by $100 \%$ compared with previous value indicating severe pain and sufferings (Alvarez, 2015). Cortisol levels remained high for four hours after disbudding (Alvarez, 2015). Pre-medication with meloxicam and injection of $1 \mathrm{ml}$ of $2 \%$ lignocaine was less stressful compared with using lignocaine alone (Chandrahas et al., 2015). Injection of meloxicam alone before disbudding have no advantage in controlling pain (IngvastLarsson et al., 2011). Use of higher doses of local anesthetics (lignocaine) alone alleviated some degree of pain in cattle (Doherty et al., 2007), however, a test done in kid with $2 \mathrm{ml}$ of $2 \%$ lignocaine did not decrease cortisol level nor any stress behaviors (Alvarez, 2009). Studies on use of more than $2 \mathrm{ml}$ of $2 \%$ lignocaine are rear or are not done in kids. On the other hand, kids are susceptible to toxic effects of using higher doses of local anesthetics (Hull, 1995; Buttle et al.,1986).

\section{Caustic chemicals (NaOH, KOH)}

Caustic chemicals such as sodium hydroxide $(\mathrm{NaOH})$ and potassium hydroxide $(\mathrm{KOH})$ in the form of stick are generally used to destroy horn producing epidermis (Vickers et al., 2005; Weaver et al., 2013). In this method, a caustic potash stick is broken off about an inch size and one end is wrapped with cloth. Hair around the bud is clipped off (Richards, 1921). Grease is applied around the bud to avoid damage by caustic potash in surrounding area. Caustic potash stick is soaked slightly before rubbing over epidermis of the bud. Caustic potash need to rub over the area about the size of five cent and continue to rub until the skin begins to break (Richards, 1921). Kids need to restrain for 30 minutes after rubbing. This method is effective when applied to 3 to 5 day old kids (Richards, 1921). Several studies were done on use of caustic chemicals and their pain assessment in calves, however, similar studies are rare in kids. Both, use or no use of local anesthesia before disbudding in calves exhibited signs of stress for longer than 3 hours (Stilwell et al., 2009). In a study, calves disbudded using caustic paste and xylazine provided less pain compared hot iron cauterization using xylazine and lidocaine (Vickers et al., 2005). In another study with calves, injection of NSAID (flunixin meglumine) and lignocaine before disbudding was found better in controlling pain compared with injection of lignocaine alone (Stilwell et al., 2009). There are several drawbacks of using caustic chemicals. If other kids lick the caustic chemical applied area then it could result their acute death (Jordan, 1990). Suckling kids can harm udder of the dam. Care also need to take to avoid leaking of caustic chemicals outside the grease. It is not recommended during raining season when animals are kept outside. This method of disbudding is still in practice in South Asian countries. In the United States and Canada neither veterinarians nor produces use caustic chemicals for disbudding kids (Valdmanis et al., 2007). 


\section{Pain minimization during dehorning and disbudding in goats and goat kids}

\section{Disbudding with Clover oil (Eugenia caryophyllata)}

In this technique, disbudding is done in 2 to 7 -day old kids. This is a simple method recently developed to minimize pain and anesthesia. At first clover oil is extracted using hydrodistillation method (Molaei et al., 2015). The active component of clover oil is Eugenol. Eugenol has NSAID like effect when injected in animals (Anpo et al., 2011). Eugenol also controls growth of neoplastic cells (Ghosh et al., 2005). Only one study is available in which authors concluded injection of $0.2 \mathrm{ml}$ of clover oil at the base of horn bud in kids (Molaei et al., 2015). It could be possible that eugenol component in the clover oil inhibited proliferation of horn germinating cell and have resulted no horn growth in experimental animals (Molaei et al., 2015). No further studies were done. Pain after disbudding with clover oil were not measured (Molaei et al., 2015). This method successfully controlled growth of horn and no complications were reported during and after the trial (Molaei et al., 2015). This method of dehorning is simple, requires less time and is farmers friendly.

\section{CONCLUSION}

Disbudding and dehorning is necessary for easy management, required by rule for dairy goat when used as a show animal and to minimize fighting between the animals (Alvarez et al., 2015; Alvarez and Gutiérrez, 2010). Plasma cortisol, an indicator for stress increases for 8 to 9 hours (Sutherland et al., 2002) and behavioral differences can be observed till two days after dehorning (Stafford and Mellor, 2005). Dehorning can also lead other complications such as tetanus, heat meningitis and brain abscess (Battini et al., 2014). Disbudding is preferred over dehorning because of less pain and less complication (Valdmanis et al., 2007). Nevertheless, cortisol level increases by $100 \%$ after disbudding indicating acute pain (Alvarez et al., 2015). Injection of $1 \mathrm{ml}$ of $2 \%$ lignocaine has no benefit in minimizing cortisol level or stress behavior after disbudding kids (Alvarez et al., 2015). Injection of slightly higher doses of lignocaine ( $2 \mathrm{ml}$ of $2 \%$ lignocaine) has no advantage (Alvarez, 2009). Studies higher than $2 \mathrm{ml}$ are not done in kids (Alvarez and Gutiérrez, 2010) because kids are susceptible to lignocaine related toxicity (Hull, 1995). Injection of meloxicam before lignocaine minimizes stress compared with using lignocaine alone (Chandrahas et al., 2015). It could be beneficial to investigate methods for disbudding that excludes the use of anesthesia. Recently a research was done using injection of oil for disbudding kids (Molaei et al., 2015). Author reported injection of clover oil controlled horn growth in kids, however, stress response was not measured (Molaei et al., 2015). Techniques that cause less stress during disbudding in kids should be adopted.

\section{REFERENCES}

1. Al-Sobayil FA (2007). A new simple device for dehorning in small ruminants. Small Ruminant Research 67: 232234.

2. Alvarez L, De Luna JB, Gamboa D, Reyes M, Sánchez A, Terrazas A, Rojas S, and Galindo F (2015). Cortisol and pain-related behavior in disbudded goat kids with and without cornual nerve block. Physiology and Behavior 138: 58-61.

3. Alvarez L and Gutiérrez J (2010). A first description of the physiological and behavioural responses to disbudding in goat kids. Animal Welfare 19: 55-59.

4. Anpo M, Shirayama K and Tsutsui T (2011). Cytotoxic effect of eugenol on the expression of molecular markers related to the osteogenic differentiation of human dental pulp cells. Odontology 99: 188-192.

5. Battini M, Vieira A, Barbieri S, Ajuda I, Stilwell G, and Mattiello S (2014). Invited review: Animal-based indicators for on-farm welfare assessment for dairy goats. Journal of Dairy Science 97: 6625-6648.

6. Buttle H, Alan M and Alastair M (1986). Disbudding and dehorning of goats. In Practice 8: 63-65.

7. Chandrahas AS and Shashi S (2015). Performance assessment of Beetal kids due to disbudding pre-medication under stall-fed conditions. Journal of Applied Animal Research 43: 69-76.

8. Gascoigne E (2015). Disbudding of goat kids. Livestock 20: 96-100.

9. Ghosh R, Nadiminty N, Fitzpatrick JE, Alworth WL, Slaga TJ, and Kumar AP (2005). Eugenol causes melanoma growth suppression through inhibition of E2F1 transcriptional activity. Journal of Biological Chemistry 280: 58125819. 
Mohan Acharya

10. Hull BL (1995) Dehorning the adult goat. Veterinary Clinics of North America: Food Animal Practice 11: 183-185.

11. Ingvast-Larsson C, Högberg M, Mengistu U, Olsen L, Bondesson U, and Olsson K (2011). Pharmacokinetics of meloxicam in adult goats and its analgesic effect in disbudded kids. Journal of Veterinary Pharmacology and Therapeutics 34: 64-69.

12. Jordan RM (1990). RP375 Angora Goats in the Midwest. Extension Animal Specialist, University of Minnesota.

13. Marongiu ML (2012). Local Anesthesia for Husbandry Procedures and Experimental Purposes in Farm Animals. Intech Open Access Publisher 242-253.

14. Molaei, MM, Mostafavi A, Kheirandish R, Azari O and Shaddel M (2015). Study of disbudding goat kids following injection of clove oil essence in horn bud region. Veterinary Research Forum 6: 17-22.

15. Richards I (1921). Modern Milk Goats: Status of the Milk Goat Industry. Methods of Profitable Milk Production. Care and Management of Commercial Herds and Household Goats. Irmagarde Richards. Philadelphia and London J. B. Lippincott Company. United States of America.

16. Shelton, JM and Haenlein GFW (2003). The University of Maryland. National goat handbook page. Meat goat production. Available at: http://outlands.tripod.com/farm/national goat handbook.pdf.

17. Stafford KJ, and Mellor DJ (2005). Dehorning and disbudding distress and its alleviation in calves. The Veterinary Journal 169: 337-349.

18. Stafford KJ and Mellor DJ (2011). Addressing the pain associated with disbudding and dehorning in cattle. Applied Animal Behaviour Science 135: 226-231.

19. Stilwell G, Carvalho RC, Lima MS, Broom DM (2009). Effect of caustic paste disbudding, using local anaesthesia with and without analgesia, on behaviour and cortisol of calves. Applied Animal Behaviour Science 116: 35-44.

20. Sutherland MA, Mellor DJ, Stafford KJ, Gregory NG, Bruce RA and Ward RN (2002). Cortisol responses to dehorning of calves given a 5-h local anaesthetic regimen plus phenylbutazone, ketoprofen, or adrenocorticotropic hormone prior to dehorning. Research in Veterinary Science 73:115-123.

21. Valdmanis L, Menzies P and Millman S (2007). A survey of dehorning practices and pain management in goats. 41st Congress of the International Society for Applied Ethology, Mérida, Mexico.

22. Vickers KJ, Niel L, Kiehlbauch LM and Weary DM (2005). Calf response to caustic paste and hot-iron dehorning using sedation with and without local anesthetic. Journal of Dairy Science 88: 1454-1459.

23. Weaver AD, Jean, GS and Steiner A (2013). Bovine surgery and lameness. $2^{\text {nd }}$ ed. Blackwell Publishing, Oxford, UK. 